\title{
Sodium in Store and Restaurant Food Environments - Guam, 2015
}

\author{
Sandra L. Jackson, $\mathrm{PhD}^{1,2}$; Brenna K. VanFrank, MD ${ }^{1,3}$; Elizabeth Lundeen, $\mathrm{PhD}^{1,3}$; Alyssa Uncangco ${ }^{4}$; Lawrence Alam ${ }^{4}$; \\ Sallyann M. Coleman King, $\mathrm{MD}^{2}$; Mary E. Cogswell, $\mathrm{DrPH}^{2}$
}

Compared with the United States overall, Guam has higher mortality rates from cardiovascular disease and stroke (1). Excess sodium intake can increase blood pressure and risk for cardiovascular disease $(2,3)$. To determine the availability and promotion of lower-sodium options in the nutrition environment, the Guam Department of Public Health and Social Services (DPHSS) conducted an assessment in September 2015 using previously validated tools adapted to include sodium measures. Stores $(\mathrm{N}=114)$ and restaurants $(\mathrm{N}=63)$ were randomly sampled by region (north, central, and south). Data from 100 stores and 62 restaurants were analyzed and weighted to account for the sampling design. Across the nine product types assessed, lower-sodium products were offered less frequently than regular-sodium products $(\mathrm{p}<0.001)$ with $<50 \%$ of stores offering lower-sodium canned vegetables, tuna, salad dressing, soy sauce, and hot dogs. Lower-sodium products were also less frequently offered in small stores than large (two or more cash registers) stores. Reduced-sodium soy sauce cost more than regular soy sauce $(\mathrm{p}<0.001)$ in stores offering both options in the same size bottle. Few restaurants engaged in promotion practices such as posting sodium information $(3 \%)$ or identifying lower-sodium entrées (1\%). Improving the availability and promotion of lower-sodium foods in stores and restaurants could help support healthier eating in Guam.

In 2010, the Pacific Islands Health Officers Association declared a regional state of health emergency in the U.S.Affiliated Pacific Islands because of an epidemic of noncommunicable diseases.* Globalization and increasing dependence on "cheap, energy-dense, high-fat foreign foods" have been cited as contributing factors in the increasing incidence of obesity and cardiovascular disease in the region $(4,5)$. Approximately 162,000 persons live on the island of Guam, which is about 30 miles long and ranges from 4 miles to 12 miles wide. ${ }^{\dagger}$ Although some regional food manufacturing (e.g., bread) occurs, most food is imported by freighter, and much of the food supply is processed to improve shelf life (G). Recognizing that the nutrition environment could be contributing to chronic disease, Guam DPHSS and its partners created the Non-Communicable Disease Strategic Plan 2014-2018 (7) to address several nutrition objectives, including reducing sodium

\footnotetext{
*http://www.pihoa.org/initiatives/policy/ncds.php.

${ }^{\dagger}$ https://www.cia.gov/library/publications/the-world-factbook/geos/gq.html.
}

consumption. Guam DPHSS, with technical assistance from $\mathrm{CDC}$, conducted this nutrition environment assessment to obtain data in support of the plan's nutrition objectives.

To identify stores and restaurants for assessment, sampling frames were created using business listings from Guam DPHSS, Division of Environmental Health, Guam Supplemental Nutrition Assistance Program (SNAP), and the local phone book. Venues were classified by region and assigned identification numbers; a random-number generator determined the order of selection of venues in each region. Three large stores, where many residents obtained groceries, were deliberately (i.e., nonrandomly) placed into the sample. Included venues were open to the public with a permanent, nonmobile structure (i.e., no food trucks or other mobile venues). Stores were included if they sold three or more of five staple foods (milk, eggs, bread, produce, or meat/fish). Restaurants were included if they had a breakfast, lunch, or dinner menu with $\geq 5$ entrées in any single category.

Stores were classified as small (one cash register) or large (two or more cash registers). Restaurants were classified as sit-down, fast-food, or fast-casual, with the second and third categories combined. Assessments used the previously validated Nutrition Environment Measures Surveys for stores and for restaurants, $\$$ after modification to better reflect the local diet and to better assess sodium. In the style of the Nutrition Environment Measures Surveys for stores, foods were classified as "lowersodium" with a corresponding "regular-sodium" counterpart to compare available consumer choices. Lower-sodium foods were classified according to Food and Drug Administration guidelines for sodium labeling, " with "no salt" foods containing no ingredient that is sodium chloride and $<5 \mathrm{mg}$ sodium per labeled serving; "low-sodium" foods containing $\leq 140 \mathrm{mg}$ sodium per serving; and "reduced-sodium" foods containing at least $25 \%$ less sodium per serving than an appropriate reference food. Lower-sodium foods assessed included no-salt-added canned vegetables; low-sodium tuna, chips, salad dressing, and bread; and reduced-sodium Spam ( $\leq 410 \mathrm{mg} /$ serving sodium), soy sauce ( $\leq 690 \mathrm{mg} / \mathrm{serving}$ ), hot dogs ( $\leq 305 \mathrm{mg} /$ serving), and instant noodles ( $\leq 730 \mathrm{mg} /$ serving). Soy sauce was an a priori selection for pricing assessment.

\footnotetext{
${ }^{\S}$ http://www.med.upenn.edu/nems/about.shtml.

Shttp://www.fda.gov/Food/GuidanceRegulation/GuidanceDocuments RegulatoryInformation/LabelingNutrition/ucm064911.htm.
} 
In all assessed venues, managers or owners were invited to participate in interviews regarding barriers to and supports for offering healthy food. However, some managers were not present and some declined to participate because of time or language barriers, leaving a convenience sample of approximately half of managers ( 50 store managers and 31 restaurant managers) who completed the sodium-related questionnaires.

Descriptive statistics were used to examine the availability and pricing of lower-sodium foods in stores, to assess sodiumrelated practices in restaurants, and to describe manager perceptions. Store and restaurant analyses were weighted to account for the survey design and disproportionate sampling across regions, but the convenience sample of managers was not weighted.

Lower-sodium alternatives typically were less available than regular-sodium product types (Table 1 ). Fewer than half of surveyed stores offered no-salt-added canned vegetables (27\%), low-sodium tuna $(10 \%)$ or salad dressing $(8 \%)$, or reducedsodium soy sauce $(43 \%)$ or hot dogs $(18 \%)$. Small stores were less likely than large stores to offer certain lower-sodium products $(\mathrm{p}<0.001)$. In stores that sold both reduced-sodium soy sauce and regular soy sauce in the same size bottle $(n=30)$, reduced-sodium soy sauce was significantly more expensive $(\$ 6.35 \pm 0.49)$ than regular-sodium soy sauce $(\$ 5.43 \pm 0.41)$, normalized to median $(20$-ounce) volume $(\mathrm{p}<0.001)$. Three fourths of store managers agreed that they should increase the availability of lower-sodium foods in their neighborhoods, but
$78 \%$ did not believe that their stores offered a large selection of lower-sodium products (Table 2).

No surveyed restaurants promoted sodium reduction in displays or table tents, and few posted sodium information at the point-ofpurchase (3\%), identified lower-sodium menu items (1\%), had salt-substitute shakers on tables $(7 \%)$, or had reduced-sodium soy sauce bottles on tables (3\%) (Table 3). Approximately one quarter of restaurants had saltshakers (27\%) on tables, and sitdown restaurants were more likely to have saltshakers on tables than fast-food restaurants $(\mathrm{p}<0.001)$. The majority of restaurant managers surveyed (65\%) were aware of efforts on Guam to reduce sodium intake; all managers who reported awareness were supportive of these efforts (100\%) (Table 2).

\section{Discussion}

This report is the first of its kind to examine sodium in the nutrition environment of Guam, including availability and promotion of lower-sodium foods in stores and restaurants. In surveyed stores, lower-sodium foods were less widely available than foods with higher sodium content, and small stores were significantly less likely than large stores to offer certain lowersodium products. Few surveyed restaurants engaged in promotion practices such as labeling sodium content on menus, but many managers reported support for sodium reduction efforts.

These findings are consistent with those from a recent report from American Samoa, another U.S.-affiliated Pacific Island, which found that healthful foods were infrequently available in

TABLE 1. Percentage of all stores, large stores, and small stores offering at least one variety of lower-sodium food, and mean total number of products available per store, by sodium content and food type - Guam, 2015*

\begin{tabular}{|c|c|c|c|c|c|c|}
\hline \multirow[b]{2}{*}{ Type of food } & \multicolumn{3}{|c|}{ Lower-sodium (\%) } & \multicolumn{3}{|c|}{ Regular-sodium (\%) } \\
\hline & $\begin{array}{l}\text { All stores } \\
(\mathrm{N}=100)\end{array}$ & $\begin{array}{l}\text { Large stores } \\
\qquad(\mathrm{n}=34)\end{array}$ & $\begin{array}{l}\text { Small stores } \\
\quad(n=66)\end{array}$ & $\begin{array}{l}\text { All stores } \\
(N=100)\end{array}$ & $\begin{array}{l}\text { Large stores } \\
\quad(n=34)\end{array}$ & $\begin{array}{l}\text { Small stores } \\
\quad(n=66)\end{array}$ \\
\hline Canned vegetables & $26.6^{\dagger}$ & $41.2^{\S}$ & 18.3 & 95.5 & $100^{\S}$ & 92.9 \\
\hline Tuna & $9.6^{+}$ & $22.5^{\S}$ & 2.2 & 59.0 & $85.2^{\S}$ & 44.0 \\
\hline Chips & $74.7^{\dagger}$ & $89.3^{\S}$ & 66.3 & 93.3 & 93.2 & 93.3 \\
\hline Salad dressing & $8.2^{\dagger}$ & $22.5^{\S}$ & 0 & 51.0 & $83.6^{\S}$ & 32.5 \\
\hline Bread & $69.2^{\dagger}$ & $86.5^{\S}$ & 59.4 & 90.7 & $100^{\S}$ & 85.5 \\
\hline Spam & $64.4^{\dagger}$ & 74.4 & 58.8 & 85.4 & 89.3 & 83.2 \\
\hline Soy sauce & $42.8^{\dagger}$ & $73.7^{\S}$ & 25.2 & 91.2 & $97.1^{\S}$ & 87.8 \\
\hline Hot dogs & 18.4 & $35.9^{\S}$ & 8.4 & 79.4 & 81.3 & 78.4 \\
\hline Instant noodles & 76.9 & $90.8^{\S}$ & 68.9 & 97.9 & 97.1 & 98.4 \\
\hline \multicolumn{7}{|c|}{ No. products per store, of nine stores assessed (mean $\pm \mathrm{SE}$ ) } \\
\hline Total & $3.9^{\text {ๆ }} \pm 0.18$ & $5.4^{* *} \pm 0.29$ & $3.1 \pm 0.16$ & $7.4 \pm 0.14$ & $8.3^{* *} \pm 0.20$ & $7.0 \pm 0.16$ \\
\hline
\end{tabular}

Abbreviation: $\mathrm{SE}=$ standard error.

* Weighted results are presented. Stores include both large (two or more cash registers) and small (one cash register) venues that are open to the public and sell at least three of the following: milk, eggs, produce, bread, or meat/fish. Lower-sodium refers to either no-salt-added (canned vegetables), low-sodium (tuna, chips, salad dressing, or bread with $\leq 140 \mathrm{mg} /$ serving sodium), or reduced-sodium (Spam with $\leq 410 \mathrm{mg} / \mathrm{serving}$, soy sauce with $\leq 690$, hot dogs with $\leq 305 \mathrm{mg}$, or instant noodles with $\leq 730 \mathrm{mg}$ ), depending on the product.

$\dagger$ Indicates significant difference $(p<0.05)$ between availability of lower-sodium versus regular-sodium options among all stores. Ideally, McNemar's test for paired proportions would be used for categorical comparisons within stores, but could not be performed with survey procedures. Survey-adjusted chi-square tests were used, which produced more conservative results than paired comparisons without survey adjustment.

$\S$ Indicates significant difference $(p<0.05)$ in availability of the same type of food (e.g., no-salt-added canned vegetables) in large versus small stores.

II Indicates significant difference $(p<0.05)$ in total number of lower-sodium versus regular-sodium options among all stores.

*** Indicates significant difference $(p<0.05)$ in total number of lower-sodium products or total number of regular-sodium products in large versus small stores. 


\begin{tabular}{|c|c|c|}
\hline Perceptions and practices & $\begin{array}{c}\text { Stores } \\
(\mathrm{n}=50) \\
(\%)\end{array}$ & $\begin{array}{c}\text { Restaurants } \\
(\mathrm{n}=31) \\
(\%)\end{array}$ \\
\hline \multicolumn{3}{|l|}{ Store/restaurant manager-reported supports and barriers (agree/strongly agree) } \\
\hline My customers look for low-salt or low-sodium foods & 18.0 & 41.9 \\
\hline Customers ask for low-salt or low-sodium foods & 34.0 & 51.6 \\
\hline I should increase the availability of low-salt or low-sodium foods in this neighborhood & 78.0 & 71.0 \\
\hline Suppliers of low-salt or low-sodium foods are hard to find & 36.0 & 29.0 \\
\hline Customers don't like low-sodium or low-salt foods, so they don't buy them & 22.0 & 9.7 \\
\hline There is a large selection of low-salt or low-sodium products in my store & 22.0 & - \\
\hline \multicolumn{3}{|l|}{ Restaurant manager perceptions and practices (answered "yes") } \\
\hline Is sodium information for menu items posted for customers to see? & - & 6.5 \\
\hline Are lower-sodium products specifically purchased for use by customers or by the chef? & - & 54.8 \\
\hline Are lower-sodium products used routinely in cooking? & - & 64.5 \\
\hline Are any vegetables routinely served without added sauce, sodium, or salad dressing? & - & 54.8 \\
\hline Are you aware of the efforts on Guam to decrease people's salt intake? & - & 64.5 \\
\hline If yes, are you supportive of the efforts to decrease people's salt intake? & - & 100.0 \\
\hline If no, would you be supportive of efforts to decrease people's salt intake? & - & 72.7 \\
\hline
\end{tabular}

* Unweighted percentages are presented.

TABLE 3. Percentage of restaurants with sodium-related promotional practices, by type of restaurant - Guam, 2015*

\begin{tabular}{|c|c|c|c|}
\hline \multirow[b]{2}{*}{ Type of promotion } & \multicolumn{3}{|c|}{ Restaurants (\%) } \\
\hline & $\begin{array}{l}\text { Total all types } \\
\qquad(\mathrm{N}=62)\end{array}$ & $\begin{array}{l}\text { Sit-down } \\
(n=43)\end{array}$ & $\begin{array}{l}\text { Fast-casual/Fast-food } \\
\qquad(\mathrm{n}=19)\end{array}$ \\
\hline Signs, table tents, or displays promote sodium reduction & 0.0 & 0.0 & 0.0 \\
\hline Sodium information is available at point-of-purchase or on the menu & 3.2 & 0.0 & 12.0 \\
\hline Menus have special icons/labels or separate sections identifying lower-sodium items & 0.8 & 1.1 & 0.0 \\
\hline Salt-substitute shakers on tables & 6.7 & 9.1 & 0.0 \\
\hline Saltshakers on tables & 27.4 & $37.5^{\dagger}$ & 0.0 \\
\hline Reduced-sodium soy sauce bottles on tables & 3.2 & 0.0 & 12.0 \\
\hline Regular soy sauce bottles on tables & 28.7 & 34.9 & 12.0 \\
\hline
\end{tabular}

* Weighted percentages are presented.

† Statistically significant difference $(p<0.05)$ between restaurant types.

stores and restaurants and often cost more and were promoted less (5). The present results provide context and data for the Guam Non-Communicable Disease Strategic Plan 2014-2018, which targets sodium reduction. For example, efforts in Guam have promoted removing saltshakers from tables in restaurants, and nearly three quarters of assessed restaurants did not have saltshakers on tables. While only a small percentage of sodium intake in the continental United States might come from a saltshaker (8), recent surveys in the Pacific islands indicate that the main sources of dietary sodium are salt and monosodium glutamate added during cooking and at the table (9). Other planned efforts in Guam include working with grocers, restaurants, and schools to increase availability of low-salt foods and meals ( 7 ). Lowering sodium content in the food supply is a recommended strategy for population-wide sodium reduction $(9,10)$.

This report is subject to at least four limitations. First, only a small selection of foods could be assessed. Efforts were made to focus on local foods that are important contributors of sodium in the diet (10), and that had both lower-sodium and regular versions for comparison. Second, price comparisons related to sodium content were restricted to soy sauce, commonly used instead of salt in cooking. Because most small stores did not have displayed prices, the number of price comparisons were limited to reduce the number of requests to store staff. Third, manager interviews were subject to selection and response bias. For example, non-English speaking managers might have been less likely to participate, although translators were used when possible. Selection bias was less likely in observational assessments of stores and restaurants; no stores and only two restaurants refused participation in the environmental assessment. Finally, sample weights could not fully account for the probability of selection of each venue, because of duplication in the sample frame. Selection probability depended on the number of times a venue was listed in the sample frame, but overall rates of duplication within the sample frame were unknown. Estimated weights were calculated with the assumption that the probability of duplication was equal for all stores in a region. Among stores (where duplication was most common), weighted and unweighted data yielded similar results. 


\section{Summary}

What is already known about this topic?

Guam has higher rates of heart disease and stroke mortality than the U.S. average. The nutrition environment might contribute to the incidence of disease, as excess sodium intake is associated with hypertension and cardiovascular disease risk.

What is added by this report?

Lower-sodium food options are less commonly available than regular-sodium products in Guam, particularly in small stores, and few restaurants currently engage in supportive practices such as menu labeling for sodium content. Most interviewed restaurant and store managers reported a desire to improve access to lower-sodium foods in their neighborhoods.

What are the implications for public health practice?

There is room for improvement in the availability and promotion of lower-sodium foods in stores and restaurants in Guam. Restaurant and store managers might be willing to engage with the public health community in support of sodium reduction efforts, one objective of Guam's Non-Communicable Disease Strategic Plan, 2014-2018.

Efforts to reduce sodium in the food supply need to involve manufacturers, vendors, and the public (9). Most managers interviewed reported a desire to improve access to lowersodium foods in their neighborhoods and might support future sodium-reduction efforts. Improving the availability, pricing, and promotion of lower-sodium foods in stores and restaurants could help to decrease sodium intake on Guam.

\section{Acknowledgments}

Roselie Zabala, Patrick Luces, Elizabeth Guerrero, Alex Silverio, Ruby Gonzales, Christopher Surla, Diana Santos, Cherisse Santiago, Vivian Pareja, Juan Santiago, Rachel Ramirez, and Venancio Imanil, Guam Department of Public Health and Social Services; Brittani Harmon, CDC; students and staff members of the University of Guam and Guam Supplemental Nutrition Assistance Program Education.
${ }^{1}$ Epidemic Intelligence Service, CDC; ${ }^{2}$ Division for Heart Disease and Stroke Prevention, National Center for Chronic Disease Prevention and Health Promotion, CDC; ${ }^{3}$ Division for Nutrition, Physical Activity, and Obesity, National Center for Chronic Disease Prevention and Health Promotion, CDC; ${ }^{4}$ Guam Department of Public Health and Social Services.

Corresponding author: Sandra L Jackson, SLJackson@cdc.gov, 770-488-4221.

\section{References}

1. Murphy SL, Kochanek KD, Xu J, Heron M. Deaths: final data for 2012. Natl Vital Stat Rep 2015;63:1-117.

2. Aburto NJ, Ziolkovska A, Hooper L, Elliott P, Cappuccio FP, Meerpohl JJ. Effect of lower sodium intake on health: systematic review and metaanalyses. BMJ 2013;346:f1326. http://dx.doi.org/10.1136/bmj.f1326

3. Mozaffarian D, Fahimi S, Singh GM, et al.; Global Burden of Diseases Nutrition and Chronic Diseases Expert Group. Global sodium consumption and death from cardiovascular causes. N Engl J Med 2014;371:624-34. http://dx.doi.org/10.1056/NEJMoa1304127

4. Hughes RG, Lawrence MA. Globalization, food and health in Pacific Island countries. Asia Pac J Clin Nutr 2005;14:298-306.

5. Lee-Kwan SH, Kumar G, Ayscue P, et al. Healthful food availability in stores and restaurants-American Samoa, 2014. MMWR Morb Mortal Wkly Rep 2015;64:276-8.

6. Snowdon W, Raj A, Reeve E, et al. Processed foods available in the Pacific Islands. Global Health 2013;9:53. http://dx.doi.org/10.1186/1744-8603-9-53

7. Guam Department of Public Health and Social Services; NonCommunicable Disease Consortium. Live healthy Guam. Guam noncommunicable disease strategic plan 2014-2018. Chalan Kareta, Mangilao, GU: Guam Department of Public Health; 2013. http://dphss. guam.gov/sites/default/files/Guam\%20Non-Communicable $\% 20$ Disease\%20Strategic\%20Plan\%202014-2018.pdf

8. Mattes RD, Donnelly D. Relative contributions of dietary sodium sources. J Am Coll Nutr 1991;10:383-93. http://dx.doi.org/10.1080/ 07315724.1991 .10718167

9. Christoforou A, Snowdon W, Laesango N, et al. Progress on salt reduction in the Pacific Islands: from strategies to action. Heart Lung Circ 2015;24:503-9. http://dx.doi.org/10.1016/j.hlc.2014.11.023

10. World Health Organization; The George Health Institute for Global Health. Salt matters for Pacific Island countries. Geneva, Switzerland: World Health Organization; 2014. http://www.wpro.who.int/ southpacific/entity/publications/salt-matters-publication.pdf 